\title{
Use of chemical fractionation to understand partitioning of biomass ash constituents during co-firing in fluidized bed combustion
}

\author{
Paula Teixeira $^{\mathrm{a}, *}$, Helena Lopes ${ }^{\mathrm{a}}$, Ibrahim Gulyurtlu ${ }^{\mathrm{a}}$, Nuno Lapa ${ }^{\mathrm{b}}$ \\ ${ }^{a}$ LNEG/UEZ, Estrada do Paço do Lumiar, 22, Ed. J, 1649-038 Lisboa, Portugal \\ ${ }^{\mathrm{b}}$ UNL-FCT-DCTB-UBiA, Quinta da Torre, 2829-516 Caparica, Portugal
}

\section{A R T I C L E I N F O}

\section{Article history:}

Received 29 September 2010

Received in revised form 2 May 2011

Accepted 13 July 2011

Available online 4 August 2011

\section{Keywords:}

Chemical fractionation

Partitioning

Ash enrichment

Biomass

Co-firing

\begin{abstract}
A B S T R A C T
Three species of biomass origin (straw pellets, olive cake and wood pellets) and two coals from different countries (Coal Polish and Coal Colombian) have been studied to understand the fate of their ash forming matter during the combustion process and to investigate the influence of co-firing biomass with coal. Three different approaches to investigate the ash behaviour were employed: (1) chemical fractionation analysis to evaluate the association/reactivity of ash forming elements in the fuels as a prediction tool, (2) establishment of elements partitioning in ash streams produced in the combustion and co-combustion trials, and (3) evaluation of enrichment factors of elements in the ash streams. The chemical fractionation analysis was applied to all fuels used to evaluate how the association/reactivity of elements making up ash may influence their behaviour during combustion. Combustion tests were carried out on a pilot scale fluidized bed combustor (FBC). Four ash streams were obtained at different locations. The uncertainty of measurements was estimated allowing a critical evaluation of mass balances over the combustion system and the partitioning of elements in the ash streams. The enrichment factors of elements in the several ash streams were estimated, incorporating uncertainties associated with analytical measurements. Results obtained showed that for FBC the relation between the chemical fractionation and the experimental partitioning is strongly affected by elutriation of particles. The element enrichment factor estimated for each ash stream, using $\mathrm{Al}$ as a reference element, revealed better correlations with the elements reactivity obtained by chemical fractionation because it overcomes particles elutriation effects. Nevertheless, it was observed that the reactivity estimated by chemical fractionation could not be solely interpreted as tendency of the elements to volatilize on FBC system, as reaction in bed zone of boiler may also occur retaining reactive elements.
\end{abstract}

(C) 2011 Elsevier Ltd. All rights reserved.

\section{Introduction}

Since the 1990s, environmental and economic related issues mostly arising from the need to decrease greenhouse gas emissions and increasing fossil fuel prices encouraged the use of renewable energy sources. The EU Directive 2009/28/EC [1] on the promotion of energy from renewable sources set targets for the share of renewables in the energy production that are constantly being reviewed in the light of the growing concerns about the climate change. However, coal still contributes to nearly $40 \%$ of worldwide electricity generation and will maintain to have an important role in the global energy supply. One way to contribute to targets of renewable share and to maintain competiveness in the energy market is the co-combustion of biomass with coal in existing installations, which allows the use of biomass without major needs for retrofitting. Biomass co-combustion with coal represents a

\footnotetext{
* Corresponding author.

E-mail address: paula.teixeira@Ineg.pt (P. Teixeira).
}

short term, low risk, low cost and sustainable reduction in net $\mathrm{CO}_{2}$ emissions, simultaneously reducing $\mathrm{SO}_{x}$ and often $\mathrm{NO}_{x}$ emissions and offering other several side benefits. Technical issues associated with co-combustion include fuel supply difficulties, security and additional handling and storage cost requirements, potential increase in corrosion of boiler tubes and decrease of overall efficiency, changes in the nature of ash deposit formation and unburned carbon and finally impact on potential ash reutilization [2].

The biomass concept can be more or less extensive, in accordance with the European Union legislation biomass is “. . the biodegradable fraction of products, waste and residues from agriculture (including vegetal and animal substances), forestry and related industries including fisheries and aquaculture, as well as the biodegradable fraction of industrial and municipal waste" [1]. More restricted is the European Standard for solid biofuels definition, CEN/TS 14588 [3] which defines biomass as a "material of biological origin excluding material embedded in geological formation and transformed to fossil". The CEN/TC 335 responsible for the 